\title{
Characterizations of $\mathbf{m}$-Normal Nearlattices in terms of Principal n-Ideals
}

\author{
M. S. Raihan \\ Dept. of Mathematics, Rajshahi University
}

\begin{abstract}
A convex subnearlattice of a nearlattice $\mathrm{S}$ containing a fixed element $\mathrm{n} \in \mathrm{S}$ is called an $\mathrm{n}$-ideal. The $\mathrm{n}$-ideal generated by a single element is called a principal $n$-ideal. The set of finitely generated principal $n-$ ideals is denoted by $\mathrm{P}_{\mathrm{n}}(\mathrm{S})$, which is a nearlattice. A distributive nearlattice $\mathrm{S}$ with 0 is called $\mathrm{m}$-normal if its every prime ideal contains at most $\mathrm{m}$ number of minimal prime ideals. In this paper, we include several characterizations of those $\mathrm{P}_{\mathrm{n}}(\mathrm{S})$ which form m-normal nearlattices. We also show that $P_{n}(S)$ is $m$-normal if and only if for any $\mathrm{m}+1$ distinct minimal prime $\mathrm{n}$-ideals $\mathrm{P}_{\mathrm{o}}, \mathrm{P}_{1}, \ldots, \mathrm{P}_{\mathrm{m}}$ of $\mathrm{S}, \mathrm{P}_{\mathrm{o}} \vee \ldots \vee \mathrm{P}_{\mathrm{m}}$ $=\mathrm{S}$.
\end{abstract}

AMS Subject Classifications (2000): 06A12, 06A99, 06B10

\section{Introduction}

Lee in [9], also see Lakser [7], has determined the lattice of all equational

subclasses of the class of all pseudo-complemented distributive lattices. They are given by

$\mathrm{B}_{-1} \subset \mathrm{B}_{\mathrm{o}} \subset \ldots \subset \mathrm{B}_{\mathrm{m}} \subset \ldots \subset \mathrm{B} \omega$, where all the inclusions are proper and $\mathrm{B} \omega$ is the class of all pseudo-complemented distributive lattices, $\mathrm{B}_{-1}$ consists of all one element algebra, $B_{o}$ is the variety of Boolean algebras while $B_{m}$, for $-1 \leq m<$ $\omega$ consists of all algebras satisfying the equation

$$
\left(\mathrm{x}_{1} \wedge \mathrm{x}_{2} \wedge \ldots \wedge \mathrm{x}_{\mathrm{m}}\right)^{*} \vee \bigvee_{i=1}^{n}\left(\mathrm{x}_{1} \wedge \mathrm{x}_{2} \wedge \ldots \wedge \mathrm{x}_{\mathrm{i}-1} \wedge \mathrm{x}_{\mathrm{i}}^{*} \wedge \mathrm{x}_{\mathrm{i}+1} \wedge \ldots \wedge \mathrm{x}_{\mathrm{m}}\right)^{*}=1
$$

where $\mathrm{x}^{*}$ denotes the pseudo-complemente of $\mathrm{x}$. Thus $\mathrm{B}_{1}$ consists of all Stone algebras.

Davey [4] has independently given several characterizations of (sectionally) $B_{m}$ and relatively $\mathrm{B}_{\mathrm{m}}$-lattices. On the other hand Cornish in [3] has studied 
distributive lattices (without pseudo-complementation) analogues to $\mathrm{B}_{\mathrm{m}}$-lattices and relatively $\mathrm{B}_{\mathrm{m}}$-lattices.

A distributive nearlattice $\mathrm{S}$ with 0 is called m-normal if each prime ideal of $\mathrm{L}$ contains at most $\mathrm{m}$-minimal prime ideals. For a fixed element $\mathrm{n} \in \mathrm{S}$, a convex subnearlattice containing $\mathrm{n}$ is called an $\mathrm{n}$-ideal. An $\mathrm{n}$-ideal generated by a finite number of elements $a_{1}, a_{2}, \ldots, a_{n}$ is called a finitely generated $n$-ideal, denoted by $<\mathrm{a}_{1}, \mathrm{a}_{2}, \ldots, \mathrm{a}_{\mathrm{n}}>_{\mathrm{n}}$. The set of all finitely generated $\mathrm{n}$-ideals is a nearlattice denoted by $F_{n}(S)$. An n-ideal generated by a single element is called a principal $n$-ideal is denoted by $\mathrm{P}_{\mathrm{n}}(\mathrm{S})$.

In this paper we include several characterizations of those $P_{n}(S)$ which form mnormal nearlattices. We show that $\mathrm{P}_{\mathrm{n}}(\mathrm{S})$ is $\mathrm{m}$-normal if and only if for any $\mathrm{m}+1$ distinct minimal prime n-ideals $\mathrm{P}_{\mathrm{o}}, \mathrm{P}_{1, \ldots}, \mathrm{P}_{\mathrm{m}}$ of $\mathrm{S}, \mathrm{P}_{\mathrm{o}} \vee \ldots \vee \mathrm{P}_{\mathrm{m}}=\mathrm{S}$.

We start the paper with the following result on n-ideals due to Latif and Noor [8]. Lemma 1.1 For a central element $n \in S, P_{n}(S) \cong(n]^{d} \times[n)$.

Following result is also essential for the development of this paper, which is due to Ali [1,Theorem 1.1.12].

Lemma 1.2 Let $\mathrm{S}$ be a distributive near-lattice with an upper element $\mathrm{n}$ and let $\mathrm{I}, \mathrm{J}$ be two $\mathrm{n}$-ideals of $\mathrm{S}$. Then for any $\mathrm{x} \in \mathrm{I} \vee \mathrm{J}, \mathrm{x} \vee \mathrm{n}=\mathrm{i} \vee \mathrm{j}$ and $\mathrm{x} \wedge \mathrm{n}=\mathrm{i}^{\prime} \wedge$ $\mathrm{j}^{\prime}$ for some $\mathrm{i}, \mathrm{i}^{\prime} \in \mathrm{I}, \mathrm{j}, \mathrm{j}^{\prime} \in \mathrm{J}$ with $\mathrm{i}, \mathrm{j} \geq \mathrm{n}$ and $\mathrm{i}^{\prime}, \mathrm{j}^{\prime} \leq \mathrm{n}$.

Now we include the following result which is due to Noor and Ali [10] and this is a generalization of [2, Lemma 3.6].

A prime $\mathrm{n}$-ideal $\mathrm{P}$ is said to be a minimal prime $\mathrm{n}$-ideal belonging to $\mathrm{n}$-ideal $\mathrm{I}$ if

(i) $\mathrm{I} \subseteq \mathrm{P}$ and

(ii) There exists no prime $\mathrm{n}$-ideal $\mathrm{Q}$ such that $\mathrm{Q} \neq \mathrm{P}$ and $\mathrm{I} \subseteq \mathrm{Q} \subseteq \mathrm{P}$. 
A prime $\mathrm{n}$-ideal $\mathrm{P}$ of a nearlattice $\mathrm{S}$ is called a minimal prime $\mathrm{n}$-ideal if there exists no prime $\mathrm{n}$-ideal $\mathrm{Q}$ such that $\mathrm{Q} \neq \mathrm{P}$ and $\mathrm{Q} \subseteq \mathrm{P}$. Thus a minimal prime $\mathrm{n}$ ideal is a minimal prime $n$-ideal belonging to $\{\mathrm{n}\}$.

Following lemma will be needed for further development of this paper. This is [3, Lemma 3.6] and is easy to prove. So we omit the proof.

The following result is [4, Lemma 2.2] which also follows from the corresponding result for commutative semi-groups due to Kist [6].

Lemma 1.3 Let $\mathrm{M}$ be a prime ideal containing an ideal $\mathrm{J}$ in a distributive medial nearlattice. Then $\mathrm{M}$ is a minimal prime ideal belonging to $\mathrm{J}$ if and only if for all $\mathrm{x} \in \mathrm{M}$, there exists $\mathrm{x}^{\prime} \notin \mathrm{M}$ such that $\mathrm{x} \wedge \mathrm{x}^{\prime} \in \mathrm{J}$.

Now we generalize this result for n-ideals.

Lemma 1.4 Let $\mathrm{n}$ be a medial element and $\mathrm{M}$ be a prime $\mathrm{n}$-ideal containing an $\mathrm{n}$-ideal $\mathrm{J}$. Then $\mathrm{M}$ is a minimal prime $\mathrm{n}$-ideal belonging to $\mathrm{J}$ if and only if for all $\mathrm{x} \in \mathrm{M}$ there exists $\mathrm{x}^{\prime} \notin \mathrm{M}$ such that $\mathrm{m}\left(\mathrm{x}, \mathrm{n}, \mathrm{x}^{\prime}\right) \in \mathrm{J}$.

Proof. Let $\mathrm{M}$ be a minimal prime $\mathrm{n}$-ideal belonging to $\mathrm{J}$ and $\mathrm{x} \in \mathrm{M}$. Then by [11], $<<\mathrm{a}>_{\mathrm{n}}, \mathrm{J}>\not \subset \mathrm{M}$. So there exists $\mathrm{x}^{\prime}$ with $\mathrm{m}\left(\mathrm{x}, \mathrm{n}, \mathrm{x}^{\prime}\right) \in \mathrm{J}$ such that $\mathrm{x}^{\prime} \notin \mathrm{M}$.

Conversely, suppose $x \in M$, then there exists $x^{\prime} \notin M$ such that $m\left(x, n, x^{\prime}\right) \in J$. This implies $\mathrm{x}^{\prime} \notin \mathrm{M}$, but $\left.\mathrm{x}^{\prime} \in<<\mathrm{x}>_{\mathrm{n}}, \mathrm{J}\right\rangle$, that is $\left\langle<\mathrm{x}>_{\mathrm{n}}, \mathrm{J}\right\rangle \not \subset \mathrm{M}$. Hence by [10], M is a prime n-ideal belonging to $\mathrm{J}$.

Davey in [4, Corollary 2.3] used the following result in proving several equivalent conditions on $\mathrm{B}_{\mathrm{m}}$-lattices. On the other hand, Cornish in [3] has used this result in studing n-normal lattices.

Proposition 1.5 Let $\mathrm{M}_{0}, \ldots, \mathrm{M}_{\mathrm{n}}$ be $\mathrm{n}+1$ distinct minimal prime ideals of a distributive nearlattice $S$. Then there exists $a_{0}, a_{1}, \ldots ., a_{n} \in S$ such that $a_{i} \wedge a_{j} \in J$ $(\mathrm{i} \neq \mathrm{j})$ and $\mathrm{a}_{\mathrm{j}} \notin \mathrm{M}_{\mathrm{j}}, \mathrm{j}=0,1, \ldots, \mathrm{n}$.

Now we generalize the above result in terms of n-ideals.

Proposition 1.6 Let $S$ be a distributive nearlattice and $n \in S$ is medial. Suppose $\mathrm{M}_{\mathrm{o}}, . ., \mathrm{M}_{\mathrm{m}}$ be $\mathrm{m}+1$ distinct minimal prime $\mathrm{n}$-ideals containing $\mathrm{n}$-ideal $\mathrm{J}$. Then 
there exists $a_{0}, a_{1}, \ldots, a_{n} \in S$ such that $m\left(a_{i}, n, a_{j}\right) \in J \quad(i \neq j)$ and $a_{j} \notin M_{j} \quad(j=0$, $1, \ldots, \mathrm{m})$.

Proof. Let $\mathrm{n}=1$. Let $\mathrm{x}_{0} \in \mathrm{M}_{1}-\mathrm{M}_{\mathrm{o}}$ and $\mathrm{x}_{1} \in \mathrm{M}_{\mathrm{o}}-\mathrm{M}_{1}$. Then by Lemma 1.3, there exists $\mathrm{x}_{1}{ }^{\prime} \notin \mathrm{M}_{\mathrm{o}}$ such that $\mathrm{m}\left(\mathrm{x}_{0}, \mathrm{n}, \mathrm{x}_{1}{ }^{\prime}\right) \in \mathrm{J}$. Hence $\mathrm{a}_{1}=\mathrm{x}_{1}, \mathrm{a}_{\mathrm{o}}=\mathrm{m}\left(\mathrm{x}_{0}, \mathrm{n}, \mathrm{x}_{1}{ }^{\prime}\right)$ are the required elements.

Observe that $m\left(a_{0}, n, a_{1}\right)=m\left(m\left(x_{0}, n, x_{1}^{\prime}\right), n, x_{1}\right)$

$$
\begin{aligned}
& =\left(\mathrm{x}_{\mathrm{o}} \wedge \mathrm{x}_{1} \wedge \mathrm{x}_{1}{ }^{\prime}\right) \vee\left(\mathrm{x}_{\mathrm{o}} \wedge \mathrm{n}\right) \vee\left(\mathrm{x}_{1} \wedge \mathrm{n}\right) \vee\left(\mathrm{x}_{1}{ }^{\prime} \wedge \mathrm{n}\right) \\
& =\left(\mathrm{x}_{\mathrm{o}} \wedge \mathrm{m}\left(\mathrm{x}_{1}, \mathrm{n}, \mathrm{x}_{1}{ }^{\prime}\right)\right) \vee\left(\mathrm{x}_{\mathrm{o}} \wedge \mathrm{n}\right) \vee\left(\mathrm{m}\left(\mathrm{x}_{1}, \mathrm{n}, \mathrm{x}_{1}{ }^{\prime}\right) \wedge \mathrm{n}\right) \\
& =\mathrm{m}\left(\mathrm{x}_{0}, \mathrm{n}, \mathrm{m}\left(\mathrm{x}_{1}, \mathrm{n}, \mathrm{x}_{1}{ }^{\prime}\right)\right)
\end{aligned}
$$

Now, $m\left(x_{1}, n, x_{1}{ }^{\prime}\right) \wedge \mathrm{n} \leq \mathrm{m}\left(\mathrm{x}_{0}, \mathrm{n}, \mathrm{m}\left(\mathrm{x}_{1}, \mathrm{n}, \mathrm{x}_{1}{ }^{\prime}\right)\right)$

$$
\leq \mathrm{m}\left(\mathrm{x}_{1}, \mathrm{n}, \mathrm{x}_{1}{ }^{\prime}\right) \vee \mathrm{n}
$$

and $\mathrm{m}\left(\mathrm{x}_{1}, \mathrm{n}, \mathrm{x}_{1}{ }^{\prime}\right) \in \mathrm{J}$, so by convexity $\mathrm{m}\left(\mathrm{a}_{\mathrm{o}}, \mathrm{n}, \mathrm{a}_{1}\right) \in \mathrm{J}$.

Assume that, the result is true for $n=m-1$, and let $M_{o}, \ldots, M_{m}$ be $m+1$ distinct minimal prime $n$-ideals. Let $b_{j}(j=0,1, \ldots, m-1)$ satisfy

$\mathrm{m}\left(\mathrm{b}_{\mathrm{i}}, \mathrm{n}, \mathrm{b}_{\mathrm{j}}\right) \in \mathrm{J}(\mathrm{i} \neq \mathrm{j})$ and $\mathrm{b}_{\mathrm{j}} \notin \mathrm{M}_{\mathrm{j}}$. Now choose $\mathrm{b}_{\mathrm{m}} \in \mathrm{M}_{\mathrm{m}}-\bigcup_{\mathrm{j}=0}^{m-1} \mathrm{M}_{\mathrm{j}}$ and by Lemma 1.4 , let $b_{m^{\prime}}$ satisfy $b_{m^{\prime}} \notin M_{m}$ and $m\left(b_{m}, n, b_{m^{\prime}}\right) \in J$. Clearly, $a_{j}=m\left(b_{j}, n, b_{m}\right)(j=0, \ldots, m-1)$ and $a_{m}=b_{m^{\prime}}$, establish the result. Let $\mathrm{J}$ be an $\mathrm{n}$-ideal of a distributive lattice $\mathrm{L}$. A set of elements $\mathrm{x}_{0}, \ldots, \mathrm{x}_{\mathrm{n}} \in \mathrm{L}$ is said to be pairwise in $\mathrm{J}$ if $\mathrm{m}\left(\mathrm{x}_{\mathrm{i}}, \mathrm{n}, \mathrm{x}_{\mathrm{j}}\right)=\mathrm{n}$ for all $\mathrm{i} \neq \mathrm{j}$.

The next result is [3, Lemma 2.3] which was suggested by Hindman in $[5$, Theorem 1.8].

Lemma 1.7 Let $\mathrm{J}$ be an ideal in a distributive nearlattice $\mathrm{S}$. For a given positive integer $\mathrm{n} \geq 2$, the following conditions are equivalent.

(i) For any $\mathrm{x}_{1}, \ldots, \mathrm{x}_{\mathrm{n}} \in \mathrm{S}$ which are 'pairwise in $\mathrm{J}$ ' that is $\mathrm{x}_{\mathrm{i}} \wedge \mathrm{x}_{\mathrm{j}} \in \mathrm{J}$ for any $\mathrm{i} \neq \mathrm{j}$, there exists $\mathrm{k}$ such that $\mathrm{x}_{\mathrm{k}} \in \mathrm{J}$. 
(ii) For any ideals $\mathrm{J}_{1}, \ldots, \mathrm{J}_{\mathrm{n}}$ in $\mathrm{S}$ such that $\mathrm{J}_{\mathrm{i}} \cap \mathrm{J}_{\mathrm{j}} \subseteq \mathrm{J}$ for any $\mathrm{i} \neq \mathrm{j}$, there exists $\mathrm{k}$ such that $\mathrm{J}_{\mathrm{k}} \subseteq \mathrm{J}$.

(iii) $\quad \mathrm{J}$ is the intersection of at most $\mathrm{n}-1$ distinct prime ideals.

Our next result is a generalization of above result. This result will be needed in proving the next theorem which is the main result of this section. In fact, the following lemma is very useful in studing those $\mathrm{P}_{\mathrm{n}}(\mathrm{S})$ which are m-normal.

Lemma 1.8 Let $\mathrm{J}$ be an $\mathrm{n}$-ideal in a distributive nearlattice $\mathrm{S}$ and $\mathrm{n} \in \mathrm{S}$ is medial. For a given positive integer $\mathrm{m} \geq 2$, the following conditions are equivalent.

(i) For any $\mathrm{x}_{1}, \ldots, \mathrm{x}_{\mathrm{n}} \in \mathrm{S}$ with $\mathrm{m}\left(\mathrm{x}_{\mathrm{i}}, \mathrm{n}, \mathrm{x}_{\mathrm{j}}\right) \in \mathrm{J}$ (that is, they are pairwise in $\mathrm{J}$ ) for any $\mathrm{i} \neq \mathrm{j}$, there exists $\mathrm{k}$ such that $\mathrm{x}_{\mathrm{k}} \in \mathrm{J}$.

(ii) For any n- ideals $\mathrm{J}_{1}, \ldots, \mathrm{J}_{\mathrm{m}}$ in $\mathrm{S}$ such that $\mathrm{J}_{\mathrm{i}} \cap \mathrm{J}_{\mathrm{j}} \subseteq \mathrm{J}$ for any $\mathrm{i} \neq \mathrm{j}$, there exists $\mathrm{k}$ such that $\mathrm{J}_{\mathrm{k}} \subseteq \mathrm{J}$.

(iii) $\mathrm{J}$ is the intersection of at most $\mathrm{m}-1$ distinct prime $\mathrm{n}$ - ideals.

Proof. (i) and (ii) are easily seen to be equivalent.

(iii) $\Rightarrow$ (i). Suppose $\mathrm{P}_{1}, \mathrm{P}_{2}, \ldots, \mathrm{P}_{\mathrm{k}}$ are $\mathrm{k}(1 \leq \mathrm{k} \leq \mathrm{m}$-1) distinct prime n-ideals such that $\mathrm{J}=\mathrm{P}_{1} \cap \mathrm{P}_{2} \cap \ldots \cap \mathrm{P}_{\mathrm{k}}$. Let $\mathrm{x}_{1}, \mathrm{x}_{2}, \ldots, \mathrm{x}_{\mathrm{m}} \mathrm{S}$ be such that $\mathrm{m}\left(\mathrm{x}_{\mathrm{i}}, \mathrm{n}, \mathrm{x}_{\mathrm{j}}\right) \in \mathrm{J}$ for all $\mathrm{i} \neq \mathrm{j}$. Suppose no element $\mathrm{x}_{\mathrm{i}}$ is a member of J.Then for each $r(1 \leq r \leq k)$ there is at most one $i(1 \leq i \leq m)$ such that $x_{i} \in P_{r}$. Since $\mathrm{k}<\mathrm{m}$, there is some $\mathrm{i}$ such that $\mathrm{x}_{\mathrm{i}} \in \mathrm{P}_{1} \cap \mathrm{P}_{2} \cap \ldots \cap \mathrm{P}_{\mathrm{k}}$. (i) $\Rightarrow$ (iii). Suppose (i) holds for $\mathrm{m}=2$, then it implies that $\mathrm{J}$ is a prime $\mathrm{n}$-ideal. Then (iii) is trivially true. Thus we may assume that there is a largest integer $t$ with $2 \leq \mathrm{t}<\mathrm{m}$ such that the condition (i) does not hold for $\mathrm{J}$ (consequently condition (i) holds for $\mathrm{t}+1, \mathrm{t}+2, \ldots, \mathrm{m}$ ). Then for some $2 \leq \mathrm{t}<\mathrm{m}$ we may suppose that there exist elements $a_{1}, a_{2}, \ldots, a_{t} \in L$ such that $m\left(a_{i}, n, a_{j}\right) \in J$ for $i \neq j, i=1,2, \ldots, t, j=1,2, \ldots, t$, yet $a_{1}, a_{2}, \ldots, a_{t} \notin J$. As $\mathrm{S}$ is a distributive lattice, $\left.<<\mathrm{a}_{\mathrm{i}}\right\rangle_{\mathrm{n}}, \mathrm{J}>$ is an $\mathrm{n}$-ideal for any $\mathrm{i} \in\{1,2, \ldots, \mathrm{t}\}$. Each $\left.\left.<<\mathrm{a}_{\mathrm{i}}\right\rangle_{\mathrm{n}}, \mathrm{J}\right\rangle$ is in fact a prime n-ideal. 
Firstly $\left.\left.<<\mathrm{a}_{\mathrm{i}}\right\rangle_{\mathrm{n}}, \mathrm{J}\right\rangle \neq \mathrm{S}$, since $\mathrm{a}_{\mathrm{i}} \notin \mathrm{J}$. Secondly, suppose that $\mathrm{b}$ and $\mathrm{c}$ are in $\mathrm{S}$ and $\left.\mathrm{m}(\mathrm{b}, \mathrm{n}, \mathrm{c}) \in\left\langle<\mathrm{a}_{\mathrm{i}}\right\rangle_{\mathrm{n}}, \mathrm{J}\right\rangle$. Consider the set of $\mathrm{t}+1$ elements $\left\{\mathrm{a}_{1}, \mathrm{a}_{2}, \ldots, \mathrm{a}_{\mathrm{i}-1}\right.$, $\left.m\left(b, n, a_{i}\right), m\left(c, n, a_{i}\right), a_{i+1}, \ldots, a_{t}\right\}$. This set is pairwise in $J$ and so, either $\mathrm{m}\left(\mathrm{b}, \mathrm{n}, \mathrm{a}_{\mathrm{i}}\right) \in \mathrm{J}$ or $\mathrm{m}\left(\mathrm{c}, \mathrm{n}, \mathrm{a}_{\mathrm{i}}\right) \in \mathrm{J}$. Since condition (i) holds for $\mathrm{t}+1$.

That is, $\mathrm{b} \in<<\mathrm{a}_{\mathrm{i}}>_{\mathrm{n}}, \mathrm{J}>$ or $\mathrm{c} \in<<\mathrm{a}_{\mathrm{i}}>_{\mathrm{n}}, \mathrm{J}>$ and so $<<\mathrm{a}_{\mathrm{i}}>_{\mathrm{n}}, \mathrm{J}>$ is prime.

Clearly, $\mathrm{J} \subseteq \bigcap_{1 \leq i \leq t}<<\mathrm{a}_{\mathrm{i}}>_{\mathrm{n}}, \mathrm{J}>$. If $\mathrm{w} \in \bigcap_{1 \leq i \leq t}<<\mathrm{a}_{\mathrm{i}}>_{\mathrm{n}}, \mathrm{J}>$. Then $\mathrm{w}, \mathrm{a}_{1}, \mathrm{a}_{2}, \ldots, \mathrm{a}_{\mathrm{t}}$ are pairwise in $\mathrm{j}$ and so $\mathrm{w} \in \mathrm{J}$. Hence $\mathrm{J}=\bigcap_{1 \leq i \leq t}<<\mathrm{a}_{\mathrm{i}}>_{\mathrm{n}}, \mathrm{J}>$ is the intersection of $\mathrm{t}<$ $\mathrm{m}$ prime n-ideals.

An ideal $\mathrm{J} \neq \mathrm{S}$ satisfying the equivalent conditions of Lemma 1.7. is called an $\mathrm{m}-$ prime ideal. Similarly, an $\mathrm{n}$-ideal $\mathrm{J} \neq \mathrm{S}$ satisfying the equivalent conditions of Lemma 1.8. is called an m-prime n-ideal.

For $\mathrm{a}, \mathrm{b} \in \mathrm{S},<\mathrm{a}, \mathrm{b}>=\{\mathrm{x} \in \mathrm{S}: \mathrm{x} \wedge \mathrm{a} \leq \mathrm{b}\}$ is known as annihilator of a relative to $\mathrm{b}$ or simply a relative annihilator. In presence of distributivity, it is easy to show that each relative annihilator is an ideal. Again for $a, b \in L$, where $L$ is a lattice, we define

$<\mathrm{a}, \mathrm{b}>_{\mathrm{d}}=\{\mathrm{x} \in \mathrm{L}: \mathrm{x} \vee \mathrm{a} \geq \mathrm{b}\}$ is a relative dual annihilator. In presence of distributivity of $\mathrm{L},<\mathrm{a}, \mathrm{b}>_{\mathrm{d}}$ is a dual ideal (filter).

For $\mathrm{a}, \mathrm{b} \in \mathrm{S}$ and an upper element $\mathrm{n} \in \mathrm{S}$, we define, $<\mathrm{a}, \mathrm{b}>^{\mathrm{n}}=\left\{\mathrm{x} \in \mathrm{S}: \mathrm{m}(\mathrm{a}, \mathrm{n}, \mathrm{x}) \in<\mathrm{b}>_{\mathrm{n}}\right\}$

$$
=\{\mathrm{x} \in \mathrm{S}: \mathrm{b} \wedge \mathrm{n} \leq \mathrm{m}(\mathrm{a}, \mathrm{n}, \mathrm{x}) \leq \mathrm{b} \vee \mathrm{n}\} .
$$

We call $<\mathrm{a}, \mathrm{b}\rangle^{\mathrm{n}}$ the annihilator of a relative to $\mathrm{b}$ around the element $\mathrm{n}$ or simply a relative n-annihilator. It is easy to see that for all $\mathrm{a}, \mathrm{b} \in \mathrm{S},<\mathrm{a}, \mathrm{b}>^{\mathrm{n}}$ is always a convex subset containing $\mathrm{n}$. In presence of distributivity, it can easily be seen that $<\mathrm{a}, \mathrm{b}>^{\mathrm{n}}$ is an n-ideal. If $0 \in \mathrm{S}$, then putting $\mathrm{n}=0$, we have, $<\mathrm{a}, \mathrm{b}>^{\mathrm{n}}=<\mathrm{a}, \mathrm{b}>$. 
For two n-ideals $A$ and $B$ of a nearlattice $S, \quad<A, B>$ denotes $\{x \in S: m(a, n$, $\mathrm{x}) \in \mathrm{B}$ for all $\mathrm{a} \in \mathrm{A}\}$, when $\mathrm{n}$ is a medial element. In presence of distributivity, clearly $<\mathrm{A}, \mathrm{B}>$ is an n-ideal.

Now we generalize a result of Davey in [4, Proposition 3.1.].

Theorem 1.9 Let $\mathrm{J}$ be an $\mathrm{n}$-ideal of a distributive nearlattice $\mathrm{S}$ and $\mathrm{n}$ be $a$ central element of $\mathrm{S}$. Then the following conditions are equivalent.

(i) For any $\mathrm{m}+1$ distinct prime $\mathrm{n}$-ideals $\mathrm{P}_{\mathrm{o}}, \mathrm{P}_{1}, \ldots, \mathrm{P}_{\mathrm{m}}$ belonging to

$\mathrm{J}, \mathrm{P}_{\mathrm{o}} \vee \mathrm{P}_{1} \vee \ldots \vee \mathrm{P}_{\mathrm{m}}=\mathrm{S}$.

(ii) Every prime n-ideal containing J contains at most $m$ distinct minimal prime $\mathrm{n}$-ideals belonging to $\mathrm{J}$.

(iii) If $\mathrm{a}_{\mathrm{o}}, \mathrm{a}_{1}, \ldots, \mathrm{a}_{\mathrm{m}} \in \mathrm{S}$ with $\mathrm{m}\left(\mathrm{a}_{\mathrm{i}}, \mathrm{n}, \mathrm{a}_{\mathrm{j}}\right) \in \mathrm{J}(\mathrm{i} \neq \mathrm{j})$ then $\underset{j}{\vee}<<\mathrm{a}_{\mathrm{j}}>_{\mathrm{n}}, \mathrm{J}>=\mathrm{S}$.

Proof. (i) $\Rightarrow$ (ii) is obvious.

(ii) $\Rightarrow$ (iii). Assume $a_{0}, a_{1}, \ldots, a_{m} \in S$ with $m\left(a_{i}, n, a_{j}\right) \in J$ and $\underset{j}{\vee}<<\mathrm{a}_{\mathrm{j}}>_{\mathrm{n}}, \mathrm{J}>\neq \mathrm{S}$. It follows that $\mathrm{a}_{\mathrm{j}} \notin \mathrm{J}$, for all $\mathrm{j}$. Then by [8], there exists a prime n-ideal P such that $\underset{j}{\vee}<<\mathrm{a}_{\mathrm{j}}>_{\mathrm{n}}, \mathrm{J}>\subseteq \mathrm{P}$. But by [11], we know that $\mathrm{P}$ is either a prime ideal or a prime filter.

Suppose $P$ is a prime ideal. For each $j$, let $F_{j}=\left\{x \wedge y: x \geq a_{j}, x, y \geq n, y \notin P\right\}$.

Let $x_{1} \wedge y_{1}, x_{2} \wedge y_{2} \in F_{j}$.

Then $\left(\mathrm{x}_{1} \wedge \mathrm{y}_{1}\right) \wedge\left(\mathrm{x}_{2} \wedge \mathrm{y}_{2}\right)=\left(\mathrm{x}_{1} \wedge \mathrm{x}_{2}\right) \wedge\left(\mathrm{y}_{1} \wedge \mathrm{y}_{2}\right)$

Now, $x_{1} \wedge x_{2} \geq a_{j}$ and $y_{1} \wedge y_{2}=m\left(y_{1}, n, y_{2}\right)$. So $t \geq x \wedge y$ implies $t=(t \vee x) \wedge(t \vee y)$. Since $y \notin P$, so $t \vee y \notin P$. Hence $t \in F_{j}$, and so $F_{j}$ is a dual ideal.

We now show that $F_{j} \cap J=\phi$, for all $j=0,1,2, \ldots$, m. If not let $b \in F_{j} \cap J$, then $b=x \wedge y, x \geq a_{j}, x, y \geq n, y \notin P$. Hence $m\left(a_{j}, n, y\right)=\left(a_{j} \wedge n\right) \vee n \vee\left(a_{j} \wedge y\right)$ $=\left(a_{j} \wedge y\right) \vee n=\left(a_{j} \vee n\right) \wedge(y \vee n)$. But $\left(a_{j} \vee n\right) \wedge(y \vee n) \in F_{j}$ and 
$\mathrm{n} \leq\left(\mathrm{a}_{\mathrm{j}} \wedge \mathrm{y}\right) \vee \mathrm{n} \leq \mathrm{b}$ implies $\mathrm{m}\left(\mathrm{a}_{\mathrm{j}}, \mathrm{n}, \mathrm{y}\right) \in \mathrm{J}$. Therefore, $\mathrm{m}\left(\mathrm{a}_{\mathrm{j}}, \mathrm{n}, \mathrm{y}\right) \in \mathrm{F}_{\mathrm{j}} \cap \mathrm{J}$.

Again, $\mathrm{m}\left(\mathrm{a}_{\mathrm{j}}, \mathrm{n}, \mathrm{y}\right) \in \mathrm{J}$ with $\mathrm{y} \notin \mathrm{P}$ implies $<<\mathrm{a}_{\mathrm{j}}>_{\mathrm{n}}, \mathrm{J}>\not \subset \mathrm{P}$, which is a contradiction. Hence $F_{j} \cap J=\phi$ for all $j$. For each $j$, let $P_{j}$ be a minimal prime nideal belonging to $J$ and $F_{j} \cap P_{j}=\phi$. Let $y \in P_{j}$. If $y \notin P$, then $y \vee n \notin P$.

Then $m\left(a_{j}, n, y \vee n\right)=\left(a_{j} \vee n\right) \wedge(y \vee n) \in F_{j}$.

But $\mathrm{m}\left(\mathrm{a}_{\mathrm{j}}, \mathrm{n}, \mathrm{y} \vee \mathrm{n}\right) \in<\mathrm{y} \vee \mathrm{n}>_{\mathrm{n}} \subseteq<\mathrm{y}>_{\mathrm{n}} \subseteq \mathrm{P}_{\mathrm{j}}$, which is a contradiction.

So $y \in P$. Therefore $P_{j} \subseteq P$, and $a_{j} \notin P_{j}$. For if $a_{j} \in P_{j}$, then $a_{j} \vee n \in P_{j}$.

Now, $a_{j} \vee n=\left(a_{j} \vee n\right) \wedge\left(a_{j} \vee n \vee y\right) \in F_{j}$ for any $y \notin P$. This implies $P_{j} \cap F_{j} \neq \varnothing$, which is a contradiction. So, $a_{j} \notin P_{j}$. But $m\left(a_{i}, n, a_{j}\right) \in J \subseteq P_{j}(i \neq j)$ which implies $a_{i} \in P_{j} \quad(i \neq j)$ as $P_{j}$ is prime. It follows that $P_{j}$ form a set of $m+1$ distinct minimal prime $\mathrm{n}$-ideals belonging to $\mathrm{J}$ and contained in $\mathrm{P}$. This contradicts (ii).

Therefore, $\underset{j}{\vee}<<\mathrm{a}_{\mathrm{j}}>_{\mathrm{n}}, \mathrm{J}>=\mathrm{S}$.

Similarly, if $\mathrm{P}$ is filter, then a dual proof of above also shows that $\left.\left.\underset{j}{\vee}<<\mathrm{a}_{\mathrm{j}}\right\rangle_{\mathrm{n}}, \mathrm{J}\right\rangle=\mathrm{S}$, and hence (iii) holds.

(iii) $\Rightarrow$ (i). Let $\mathrm{P}_{\mathrm{o}}, \mathrm{P}_{1}, \ldots, \mathrm{P}_{\mathrm{m}}$ be $\mathrm{m}+1$ distinct minimal prime $\mathrm{n}$-ideals belonging to J. Then by Proposition 1.6, there exists

$a_{0}, a_{1}, \ldots, a_{m} \in S$ such that $m\left(a_{i}, n, a_{j}\right) \in J(i \neq j)$ and $a_{j} \notin P_{j}$. This implies $<<\mathrm{a}_{\mathrm{j}}>_{\mathrm{n}}, \mathrm{J}>\subseteq \mathrm{P}_{\mathrm{j}}$ for all $\mathrm{j}$. Then by (iii), $<<\mathrm{a}_{\mathrm{o}}>_{\mathrm{n}}, \mathrm{J}>\vee<<\mathrm{a}_{1}>_{\mathrm{n}}, \mathrm{J}>\vee \ldots \vee<<\mathrm{a}_{\mathrm{m}}>_{\mathrm{n}}, \mathrm{J}>\subseteq \mathrm{P}_{\mathrm{o}} \vee \mathrm{P}_{1} \vee \ldots \vee \mathrm{P}_{\mathrm{m}}$, which implies $\mathrm{P}_{\mathrm{o}} \vee \mathrm{P}_{1} \vee \ldots \vee \mathrm{P}_{\mathrm{m}}=\mathrm{S}$.

For a prime $\mathrm{n}$-ideal $\mathrm{P}$ of $\mathrm{S}, \mathrm{n}(\mathrm{P})=\{\mathrm{x} \in \mathrm{S}: \mathrm{m}(\mathrm{x}, \mathrm{n}, \mathrm{y})=\mathrm{n}$ for some $\mathrm{y} \in \mathrm{S}-\mathrm{P}\}$. Clearly, $\mathrm{n}(\mathrm{P})$ is an $\mathrm{n}$-ideal and $\mathrm{n}(\mathrm{P}) \subseteq \mathrm{P}$. Our next result is a nice extension of above result in terms of n-ideals.

Theorem 1.10. Let $\mathrm{S}$ be a distributive nearlattice with a central element $\mathrm{n}$. Then the following conditions are equivalent.

(i) For any $\mathrm{m}+1$ distinct minimal prime n-ideals $\mathrm{P}_{\mathrm{o}}, \mathrm{P}_{1}, \ldots ., \mathrm{P}_{\mathrm{m}}$, 
$\mathrm{P}_{\mathrm{o}} \vee \mathrm{P}_{1} \vee \ldots . \vee \mathrm{P}_{\mathrm{m}}=\mathrm{S}$.

(ii) Every prime n- ideal contains at most m minimal prime $\mathrm{n}$ - ideals.

(iii) For any $\mathrm{a}_{\mathrm{o}}, \mathrm{a}_{1}, \ldots, \mathrm{a}_{\mathrm{m}} \in \mathrm{S}$ with $\mathrm{m}\left(\mathrm{a}_{\mathrm{i}}, \mathrm{n}, \mathrm{a}_{\mathrm{j}}\right)=\mathrm{n}$ for $(\mathrm{i} \neq \mathrm{j})$, $\mathrm{i}=0,1,2,---, \mathrm{m}, \mathrm{j}=0,1,2,---, \mathrm{m},<\mathrm{a}_{\mathrm{o}}>_{\mathrm{n}}{ }^{*} \vee<\mathrm{a}_{1}>_{\mathrm{n}}{ }^{*} \vee \ldots \vee<\mathrm{a}_{\mathrm{m}}>_{\mathrm{n}}{ }^{*}=\mathrm{S}$.

(iv) For each prime $\mathrm{n}$-ideal $\mathrm{P}, \mathrm{n}(\mathrm{P})$ is an $\mathrm{m}+1$ - prime $\mathrm{n}$-ideal.

Proof. (i) $\Rightarrow$ (ii), (ii) $\Rightarrow$ (iii) and (iii) $\Rightarrow$ (i) easily hold by Theorem 1.9, replacing $\mathrm{J}$ by $\{n\}$.To complete the proof we need to show that (iv) $\Rightarrow$ (iii) and (ii) $\Rightarrow$ (iv).

(iv) $\Rightarrow$ (iii). Suppose (iv) holds and $\mathrm{x}_{0}, \mathrm{x}_{1}, \ldots, \mathrm{x}_{\mathrm{m}}$ are $\mathrm{m}+1$ elements of $\mathrm{S}$ such that $m\left(x_{i}, n, x_{j}\right)=n$ for $(i \neq j)$. Suppose that $<x_{0}>_{n}{ }^{*} \vee \ldots \vee<x_{m}>_{n}^{*} \neq S$. Then by Stone's separation theorem in [9], there is a prime n-ideal P such that $<\mathrm{x}_{\mathrm{o}}$ $>_{\mathrm{n}}{ }^{*} \vee \ldots \vee<\mathrm{x}_{\mathrm{m}}>_{\mathrm{n}}{ }^{*} \subseteq \mathrm{P}$. Hence $\mathrm{x}_{\mathrm{o}}, \mathrm{x}_{1}, \ldots, \mathrm{x}_{\mathrm{m}} \in \mathrm{S}-\mathrm{n}(\mathrm{P})$. This contradicts (iv) by Lemma 1.8, since $m\left(x_{i}, n, x_{j}\right)=n \in n(P)$ for all $i \neq j$. Thus (iii) holds.

(ii) $\Rightarrow$ (iv). This follows immediately from Lemma 1.8 口

Proposition 1.11 Let $\mathrm{S}$ be a distributive medial nearlattice and $\mathrm{n} \in \mathrm{S}$ is a central element. If the equivalent conditions of Theorem 1.10 hold, then for any $\mathrm{m}+1$ elements $\mathrm{x}_{\mathrm{o}}, \mathrm{x}_{1}, \ldots, \mathrm{x}_{\mathrm{m}} ;\left(<\mathrm{x}_{\mathrm{o}}>_{\mathrm{n}} \cap<\mathrm{x}_{1}>_{\mathrm{n}} \cap \ldots \cap<\mathrm{x}_{\mathrm{m}}>_{\mathrm{n}}\right)^{*}=$ $\underset{0 \leq i \leq n}{\vee}\left(<\mathrm{x}_{\mathrm{o}}>_{\mathrm{n}} \cap<\mathrm{x}_{1}>_{\mathrm{n}} \cap \ldots \cap<\mathrm{x}_{\mathrm{i}-1}>_{\mathrm{n}} \cap<\mathrm{x}_{\mathrm{i}+1}>_{\mathrm{n}} \cap \ldots \cap<\mathrm{x}_{\mathrm{m}}>_{\mathrm{n}}\right)^{*}$.

Proof. Let $<\mathrm{b}_{\mathrm{i}}>_{\mathrm{n}}=\left\langle\mathrm{x}_{\mathrm{o}}>_{\mathrm{n}} \cap<\mathrm{x}_{1}>_{\mathrm{n}} \cap \ldots \cap<\mathrm{x}_{\mathrm{i}-1}>_{\mathrm{n}} \cap<\mathrm{x}_{\mathrm{i}+1}>_{\mathrm{n}} \cap \ldots \cap\right.$

$<\mathrm{x}_{\mathrm{m}}>_{\mathrm{n}}$ for each $0 \leq \mathrm{i} \leq \mathrm{m}$. Suppose $\mathrm{x} \in\left(<\mathrm{x}_{\mathrm{o}}>_{\mathrm{n}} \cap<\mathrm{x}_{1}>_{\mathrm{n}} \cap \ldots \cap<\mathrm{x}_{\mathrm{m}}>_{\mathrm{n}}\right)^{*}$.

Then $<\mathrm{x}>_{\mathrm{n}} \cap<\mathrm{x}_{\mathrm{o}}>_{\mathrm{n}} \cap<\mathrm{x}_{1}>_{\mathrm{n}} \cap \ldots \cap<\mathrm{x}_{\mathrm{m}}>_{\mathrm{n}}=\{\mathrm{n}\}$. For all $\mathrm{i} \neq \mathrm{j}$,

$\left(<\mathrm{x}>_{\mathrm{n}} \cap<\mathrm{b}_{\mathrm{i}}>_{\mathrm{n}}\right) \cap\left(<\mathrm{x}>_{\mathrm{n}} \cap<\mathrm{b}_{\mathrm{j}}>_{\mathrm{n}}\right)=\{\mathrm{n}\}$.

So $\left(<\mathrm{x}>_{\mathrm{n}} \cap<\mathrm{b}_{\mathrm{o}}>_{\mathrm{n}}\right)^{*} \vee \ldots \vee\left(<\mathrm{x}>_{\mathrm{n}} \cap<\mathrm{b}_{\mathrm{m}}>_{\mathrm{n}}\right)^{*}=\mathrm{S}$.

Thus $\mathrm{x} \in\left(<\mathrm{x}>_{\mathrm{n}} \cap<\mathrm{b}_{\mathrm{o}}>_{\mathrm{n}}\right)^{*} \vee \ldots \vee\left(<\mathrm{x}>_{\mathrm{n}} \cap<\mathrm{b}_{\mathrm{m}}>_{\mathrm{n}}\right)^{*}$. Hence by Lemma 1.2, $\mathrm{x} \vee \mathrm{n}=\mathrm{a}_{\mathrm{o}} \vee \ldots \vee \mathrm{a}_{\mathrm{m}}$ where $\mathrm{a}_{\mathrm{i}} \in\left(<\mathrm{x}>_{\mathrm{n}} \cap<\mathrm{b}_{\mathrm{i}}>_{\mathrm{n}}\right)^{*}$ and $\mathrm{a}_{\mathrm{i}} \geq \mathrm{n}$ for $\mathrm{i}=0,1, \ldots, \mathrm{m}$. Then $\mathrm{x} \vee \mathrm{n}=\left(\mathrm{a}_{\mathrm{o}} \wedge(\mathrm{x} \vee \mathrm{n})\right) \vee \ldots \vee\left(\mathrm{a}_{\mathrm{m}} \wedge(\mathrm{x} \vee \mathrm{n})\right)$. 
Now $\mathrm{a}_{\mathrm{i}} \in\left(<\mathrm{x}>_{\mathrm{n}} \cap<\mathrm{b}_{\mathrm{i}}>_{\mathrm{n}}\right)^{*}$ implies $<\mathrm{a}_{\mathrm{i}}>_{\mathrm{n}} \cap<\mathrm{x}>_{\mathrm{n}} \cap<\mathrm{b}_{\mathrm{i}}>_{\mathrm{n}}=\{\mathrm{n}\}$. Then by a routine calculation we find that $\left(a_{i} \wedge x \wedge b_{i}\right) \vee n=n$

Thus $<\mathrm{a}_{\mathrm{i}} \wedge(\mathrm{x} \vee \mathrm{n})>_{\mathrm{n}} \cap<\mathrm{b}_{\mathrm{i}}>_{\mathrm{n}}=\left[\mathrm{n},\left(\mathrm{a}_{\mathrm{i}} \wedge \mathrm{x} \wedge \mathrm{b}_{\mathrm{i}}\right) \vee \mathrm{n}\right]=\{\mathrm{n}\}$ implies that $\mathrm{a}_{\mathrm{i}} \wedge(\mathrm{x} \vee \mathrm{n}) \in<\mathrm{b}_{\mathrm{i}}>_{\mathrm{n}}{ }^{*}$ and so $\mathrm{x} \vee \mathrm{n} \in<\mathrm{b}_{\mathrm{o}}>_{\mathrm{n}}{ }^{*} \vee<\mathrm{b}_{1}>_{\mathrm{n}}{ }^{*} \vee \ldots \vee<\mathrm{b}_{\mathrm{m}}>_{\mathrm{n}}{ }^{*}$. By a dual proof of above and using Theorem 1.3.7, we can easily show that $\mathrm{x} \wedge \mathrm{n} \in<\mathrm{b}_{\mathrm{o}}>_{\mathrm{n}}{ }^{*} \vee<\mathrm{b}_{1}>_{\mathrm{n}}{ }^{*} \vee \ldots \vee<\mathrm{b}_{\mathrm{m}}>_{\mathrm{n}}{ }^{*}$.

Thus by convexity, $\mathrm{x} \in<\mathrm{b}_{\mathrm{o}}>_{\mathrm{n}}{ }^{*} \vee<\mathrm{b}_{1}>_{\mathrm{n}}{ }^{*} \vee \ldots \vee<\mathrm{b}_{\mathrm{m}}>_{\mathrm{n}}{ }^{*}$.

This proves that L.H.S. $\subseteq$ R.H.S. The reverse inclusion is clear.

Theorem 1.12 Let $\mathrm{S}$ be a distributive nearlattice and $\mathrm{n} \in \mathrm{S}$ is central. Then the following conditions are equivalent.

(i) $\mathrm{P}_{\mathrm{n}}(\mathrm{S})$ is m-normal.

(ii) Every prime n-ideal contains at most m minimal prime n-ideals.

(iii) For any $\mathrm{m}+1$ distinct minimal prime $\mathrm{n}$-ideals $\mathrm{P}_{\mathrm{o}}, \ldots, \mathrm{P}_{\mathrm{m}}$; $\mathrm{P}_{\mathrm{o}} \vee \ldots \vee \mathrm{P}_{\mathrm{m}}=\mathrm{S}$.

(iv) If $\mathrm{m}\left(\mathrm{a}_{\mathrm{i}}, \mathrm{n}, \mathrm{a}_{\mathrm{j}}\right)=\mathrm{n}$, this implies $<\mathrm{a}_{\mathrm{o}}>_{\mathrm{n}}{ }^{*} \vee \ldots .<<\mathrm{a}_{\mathrm{m}}>_{\mathrm{n}}{ }^{*}=\mathrm{S}$.

(v) For each prime $\mathrm{n}$-ideal $\mathrm{P}, \mathrm{n}(\mathrm{P})$ is an $\mathrm{m}+1$ prime $\mathrm{n}$-ideal.

Proof. (i) $\Rightarrow$ (ii). Let $P_{n}(S)$ be m-normal, since $n$ is central, $P_{n}(S) \cong(n]^{d} \times[n)$, so both $(\mathrm{n}]^{\mathrm{d}}$ and $[\mathrm{n})$ are m-normal. Suppose $\mathrm{P}$ is any prime $\mathrm{n}$-ideal of $\mathrm{S}$. Then by [10], either $\mathrm{P} \supseteq(n]$ or $\mathrm{P} \supseteq[n)$. Without loss of generality, suppose $\mathrm{P} \supseteq[n)$. Then by [10], $\mathrm{P}$ is prime ideal of $\mathrm{S}$. Hence by [2, Lemma 3.4], $\mathrm{P}_{1}=\mathrm{P} \cap[\mathrm{n}$ ) is a prime ideal of [n). Since [n) is m-normal, so by [3] $P_{1}$ contains at most $m$ minimal prime ideals $R_{1}, R_{2}, \ldots, R_{m}$ of $[n$ ). Therefore, $P$ contains at most $m$ minimal prime ideals $\mathrm{T}_{1}, \mathrm{~T}_{2}, \ldots, \mathrm{T}_{\mathrm{m}}$ of $\mathrm{S}$ where $R_{1}=T_{1} \cap[n), R_{2}=T_{2} \cap[n), \ldots, R_{m}=T_{m} \cap[n)$. Since $n \in R_{1}, \ldots, R_{m}, n \in T_{1}, \ldots$, $T_{m}$, hence $T_{1}, \ldots, T_{m}$ are minimal prime n-ideals of $S$. Thus (ii) holds.

(ii) $\Rightarrow$ (i). Suppose (ii) holds. Let $\mathrm{P}_{1}$ be a prime ideal in [n). Then by [2, Lemma 3.4], $\mathrm{P}_{1}=\mathrm{P} \cap[\mathrm{n}$ ) for some prime ideal $\mathrm{P}$ of $\mathrm{S}$. Since 
$\mathrm{n} \in \mathrm{P}_{1} \subseteq \mathrm{P}$, so $\mathrm{P}$ is prime $\mathrm{n}$-ideal. Therefore, $\mathrm{P}$ contains at most $\mathrm{m}$ minimal prime n-ideals $\mathrm{R}_{1}, \ldots, \mathrm{R}_{\mathrm{m}}$ of $\mathrm{S}$. Thus by [2, Lemma 3.4], $\mathrm{P}_{1}$ contains at most $\mathrm{m}$ minimal prime ideals $T_{1}=R_{1} \cap[n), T_{2}=R_{2} \cap[n), \ldots \ldots, T_{m}=R_{m} \cap[n)$ of $[n$ ). Hence by Theorem 1.10, [n) is m-normal. Similarly, we can prove that $(n]^{d}$ is also m-normal. Thus by Lemma $1.1, \mathrm{P}_{\mathrm{n}}(\mathrm{S})$ is m-normal.

(ii) $\Leftrightarrow$ (iii) has already been proved in Theorem 1.10

\section{References}

1. M. A. Ali, A study on n-ideals of a Lattice, Ph.D. Thesis, Rajshahi University, Bangladesh (2000).

2. W. H. Cornish, Normal lattices, J. Austral. Math. Soc.14, 200$215,(1972\}$.

3. W. H. Cornish, n-Normal lattices, Proc. Amer. Math. Soc. 1(45), 4854,(1974).

4. B. A. Davey, Some annihilator conditions on distributive lattices. Algebra Universalis Vol. 4, 3, 316-322 (1974).

5. N. Hindman, Minimal n-prime ideal spaces, Math. Ann. 199, 97-114 (1972).

6. J. E. Kist, Minimal prime ideals in commutative semigroup, Proc. London Math. Soc.(3), 13, 13-50 (1973).

7. H. Lakser, The structure of pseudocomplemented distributive lattices 1,Sub direct decomposition, Trans. Amer. Math. Soc. 156, 335-342 (1971).

8. M. A. Latif and A. S. A. Noor, n-ideals of a lattice, The Rajshahi University Studies (Part B), 22, 173-180 (1994).

9. K. B. Lee, Equational classes of distributive pseudocomplemented lattices, Canad. J. Math. 22, 881-891 (1970).

10. A. S. A. Noor and M. A. Latif, Relative annihilators around a neutral element of a lattice, The Rajshahi University Studies (Part B). Vol. 28, 141-146 (2000).

11. S. A. Noor and M. A. Ali, Minimal prime n-ideals of a lattice, North Bengal University Review, (India) Vol.9, 1(1998). 